\title{
Cigarro "companheiro": o tabagismo feminino em uma abordagem crítica de gênero
}

\author{
Cigarette as "companion": a critical gender \\ approach to women's smoking
}

\author{
1 Hospital Universitário \\ Clementino Fraga Filho, \\ Universidade Federal do Rio \\ de Janeiro, Rio de Janeiro, \\ Brasil. \\ 2 Instituto de Estudos em \\ Saúde Coletiva, Universidade \\ Federal do Rio de Janeiro, \\ Rio de Janeiro, Brasil. \\ Correspondência \\ M. T. T. Borges \\ Núcleo de Estudos e \\ Tratamento do Tabagismo, \\ Instituto de Doenças do \\ Tórax, Hospital Universitário \\ Clementino Fraga Filho, \\ Universidade Federal do \\ Rio de Janeiro. \\ Av. Professor Rodolpho \\ Rocco 255, 3o andar, Prédio \\ do Hospital Universitário \\ Clementino Fraga Filho, \\ Cidade Universitária, \\ Rio de Janeiro, $R J$ \\ 21941-913, Brasil. \\ marciatrotta@iesc.ufrj.br \\ marciatrotta@gmail.com
}

\begin{abstract}
This article presents the main results of a study that examined the symbolic and material meanings of women's smoking, adopting a critical and qualitative gender approach. Semi-structured interviews were held with 14 women smokers in different stages of the smoking cessation process. The research locus was a tobacco treatment program located in a public hospital in Rio de Janeiro, Brazil. The findings showed how deeply smoking is interwoven in these women's social and gender trajectories, playing a decisive support role when they have to deal with various difficulties in life. The cigarette as a "companion" emerged as the main empirical category, as something always available to quell anxiety and loneliness, as well as a source of pleasure and relaxation. The critical gender approach evidenced how women's reproductive and productive work overload reinforces their tobacco dependency. In health care, in order to attain women smokers' adherence to the arduous cessation process, it is crucial to consider the complex relations between social and gender dimensions when cigarettes are viewed as a "companion".
\end{abstract}

Smoking; Smoking Cessation; Women
Márcia Terezinha Trotta Borges 1 Regina Helena Simões-Barbosa 2

\section{Introdução}

"Me dói mais [a morte do filho] que a fome que eu passei na infância... . [O cigarro] é pra ficar bem mais forte, porque a gente não é tão forte... . O cigarro passava a sensação.... me sentia muito forte... ." (depoimento de uma entrevistada ao expressar, em lágrimas, a dor pelo filho assassinado).

“... É uma carência, é uma luta muito solitária que a mulher tem... . Eo cigarro é o apoio" (depoimento de uma entrevistada com câncer, sem ter com quem dividir o medo da morte).

Os depoimentos acima, extraídos da pesquisa que será aqui apresentada, indicam o quanto o tema "tabagismo feminino" é complexo, abarcando da fragilidade e solidão femininas à garra e coragem de tantas mulheres que, apesar das inúmeras adversidades com que se defrontam nas labutas cotidianas, encontram forças para enfrentar e superar as muitas dificuldades do viver.

Frente a uma sociedade que continua a exigir que as mulheres sejam verdadeiros "Atlas" - o Deus da mitologia grega que carrega o mundo nas $\operatorname{costas}^{1}$ - , o cigarro torna-se, como esta pesquisa pretende revelar, um importante apoio no enfrentamento dos embates da vida, cobrando, porém, um alto preço pelo amparo e prazer proporcionados.

Os dados desta pesquisa mostram a necessidade de se identificar questões relevantes para os 
profissionais de saúde no campo do tabagismo, enfatizando a urgência de se ampliar o conhecimento e a assistência à saúde por meio de maior interlocução entre diferentes saberes. O debate interdisciplinar é, portanto, imprescindível para o avanço das práticas assistenciais em saúde, em especial aquelas relacionadas ao tabagismo.

Algumas premissas do campo da Saúde Coletiva fundamentam este trabalho que, por intermédio do aporte das Ciências Sociais e Humanas, pretende enriquecer a compreensão do "tabagismo feminino". O ponto de partida ancora-se em uma crítica ao chamado modelo biomédico que, baseado em uma concepção mecanicista de corpo, reduzido à sua dimensão biológica individual, desconsidera as outras dimensões da vida humana e, assim, reduz a assistência à saúde a uma intervenção orgânica, individual, racional e objetiva $1,2,3$. Nesse modelo, ainda hegemônico, a busca por sinais e sintomas visando a uma intervenção "técnica" relega a um segundo plano os determinantes sócio-culturais, políticos e subjetivos que perpassam os processos saúde e doença, o que inclui, como é aqui postulado, a dimensão de gênero.

As atuais estratégias assistenciais para o enfrentamento do tabagismo, divulgadas por meio de consensos e políticas governamentais, por vezes desconsideram, reduzem ou simplificam as complexas dimensões da vida humana. Escapam a esse modelo, de forma fugaz, tanto a subjetividade dos sujeitos implicados quanto as determinações sócio-econômicas e culturais que perpassam as singularidades humanas, incluso as contradições de gênero. Assim, propomos aqui que, enquanto profissionais de saúde, seja no campo da teoria ou da prática profissional, devemos questionar e repensar nossos olhares e posturas se pretendemos, ao invés de, simplesmente, "retirar o cigarro", efetivamente apoiar os tabagistas, homens e mulheres, no esforço para se libertarem de uma severa dependência que acarreta tão graves implicações à vida e à saúde.

Em se tratando de mulheres tabagistas, o presente trabalho parte de um campo de conhecimento teórico e empírico ainda inexplorado, sem referências de estudos que utilizem a abordagem de gênero. Em artigo anterior 4, empreendemos uma leitura sociológica crítica sobre as tendências epidemiológicas do tabagismo que confirmaram o quanto as determinações de gênero estão (também) entrelaçadas a este problema.

No presente estudo, apresentamos os resultados de uma pesquisa realizada em 2006 que investigou, por meio de abordagem qualitativa, as marcas de gênero no "fumar feminino" em mulheres tabagistas que freqüentavam um pro- grama de cessação em um hospital público do Rio de Janeiro, Brasil 5.

\section{Referencial teórico-metodológico}

Para a análise do "fumar feminino", partimos do paradigma conceitual das Ciências Sociais e Humanas, adotando, particularmente, um conceito crítico de gênero. Ao considerar como dimensões constituintes do universo humano a subjetividade, a representação simbólica e os significados atribuídos pelos sujeitos ao fenômeno em análise, e entendendo que estas dimensões estão dialeticamente relacionadas às condições sociais mais amplas, este referencial permite a superação da abordagem restrita ao risco epidemiológico, conferindo à análise maior abrangência, integralidade e contextualização. Pretende, assim, subsidiar as possíveis (e desejáveis) transformações das práticas assistenciais, rumo a uma assistência integral à saúde, tal como proposto, há décadas, pelo movimento de mulheres 3,6.

O conceito de gênero transversal, tal como aqui postulado, considera que a dimensão de gênero está entrelaçada às de classe social e raça/etnia 5,6,7,8,9,10,11. Conceitualmente, insere a dimensão de gênero no interior das outras relações sociais e, dialeticamente, reconhece as desigualdades sociais dentro das relações de gênero, não se descolando das condições materiais de existência que circundam e condicionam as possibilidades de escolha e autodeterminação dos indivíduos, homens e mulheres. No presente trabalho, esse referencial busca relacionar o fumar feminino às condições objetivas e subjetivas das mulheres na (desigual) sociedade brasileira, considerando-se a dialética entre as esferas produtiva e reprodutiva.

Metodologicamente, a abordagem qualitativa adotada visou a captar e compreender as vivências subjetivas, simbólicas e concretas dos sujeitos da pesquisa, além de fortalecer, epistemologicamente, uma concepção de ciência ancorada no diálogo e na possibilidade de construção compartilhada do conhecimento 12,13. O tratamento dos dados foi realizado usando-se a abordagem hermenêutico-dialética, buscandose captar, no discurso dos(as) sujeitos(as) da pesquisa, o movimento dialético da sociedade em suas expressões materiais e simbólicas, objetivas e subjetivas. Para o referencial hermenêuticodialético, a fala, o depoimento, a narrativa são resultantes de um processo social e de um processo de conhecimento, cada qual com significado específico, porém, articulados entre si 14,15.

O instrumento de coleta dos dados foi a entrevista semi-estruturada; por meio dela, bus- 
cou-se captar as dimensões das experiências de vida, sentimentos, crenças, valores e atitudes das entrevistadas, além das singularidades em meio às diversidades culturais e sociais 16 . Os temas abordados foram as trajetórias de gênero entrelaçadas às histórias sócio-familiares, as experiências com o tabaco, a compreensão sobre os significados do "fumar feminino" e, por fim, a avaliação do programa de saúde oferecido.

O lócus do estudo foi um programa de cessação do tabagismo de um hospital público federal situado no Município do Rio de Janeiro, Brasil. Foram realizadas 14 entrevistas, com duração média de uma hora e meia cada. O universo estudado abarcou mulheres em diferentes etapas de tratamento, com vistas a incorporar a diversidade de situações e momentos deste processo.

A pesquisa foi submetida ao Comitê de Ética em Pesquisa do referido hospital e a adesão ao estudo foi efetivada pelo Termo de Consentimento Livre e Esclarecido, elaborado conforme o capítulo IV da Resolução $n^{o}$. 196/96 do Conselho Nacional de Saúde.

\section{Uma breve apresentação das entrevistadas}

A maioria delas (11) encontrava-se entre os $41 \mathrm{e}$ 60 anos de idade; duas tinham menos de 40 anos e apenas uma mais de 60 anos.

Metade das entrevistadas possuía baixa escolaridade. Porém, como esse programa também é procurado por profissionais do hospital, três entrevistadas tinham nível superior completo.

Quanto à idade de iniciação no tabagismo, três delas começaram a fumar entre 5 e 10 anos; nove, entre 11 e 15; e duas, entre 16 e 19 anos. Surpreendeu constatar que a maioria (9) experimentou os primeiros cigarros em casa, acendendo-os para familiares próximos. As demais iniciaram na adolescência, com colegas de escola ou trabalho. Quanto ao tempo de tabagismo ativo, quatro entrevistadas têm entre 25 e 30 anos, e dez mais de 30 anos.

Quanto ao tempo de abstinência na ocasião da entrevista, duas entrevistadas ainda fumavam, sete se encontravam em abstinência - entre 2 e 6 meses - e quatro há mais de um ano.

Sobre os motivos para a cessação, a preocupação com a saúde foi a principal razão alegada, já que a maioria (10) apresentava problemas de saúde potencializados pelo uso do cigarro. Dessas, apenas três foram orientadas por um médico a procurar ajuda, o que sugere uma grave lacuna no atendimento à saúde da população.

\section{Histórias de vida: iniciando uma reflexão de gênero}

Tendo por objetivo apreender as formas como o fumar feminino está imbricado nas trajetórias constitutivas da identidade de gênero, as entrevistadas foram convidadas a trazer à cena da entrevista suas histórias de vida e seus contextos sócio-familiares. É importante destacar que a pesquisa abordou mulheres maduras, com vidas relativamente estabilizadas e uma capacidade de reflexão crítica facilitada pela maturidade.

Infância e juventude: a dura luta pela sobrevivência

As histórias narradas revelaram um cenário de infância e adolescência marcado por privações materiais, chegando, em alguns casos extremos, à dolorosa experiência da fome. Para 9 entrevistadas, a situação familiar agravou-se após o abandono ou falecimento paterno. O depoimento de Vilma ilustra bem essas condições adversas: “... quando eu completei 12 anos, o meu pai sofreu um acidente... aí, mamãe não tinha como dar comida pra gente... e eu me lembro que ela foi na escola e tirou a gente pra trabalhar... . Eu fui ser babá... parei de estudar e chorei muito, porque eu tinha o maior prazer de ir pro colégio, mesmo de chinelo de dedo... eu não me importava, sabe... foi muito sacrificado, a gente acordava de manhã, não tinha nem o que comer".

A maioria das narrativas apontou, em geral, para um processo de fragmentação sócio-familiar que se iniciava na ausência da figura paterna, levando suas mães a assumirem o papel de provedoras e constituindo, assim, as "famílias chefiadas por mulheres", comprovadamente as mais empobrecidas 9,6,17,18.

As brincadeiras de infância foram, para muitas delas, substituídas pelo drama do trabalho infantil, que interrompia precocemente a escolarização: "Eu comecei a trabalhar, praticamente... eu não tinha nem 8 anos ainda... eu carreguei muita pedra [em obra], assim, nas latinhas de cinco [litros] de tinta, pra comprar um açúcar, um pão... a gente não tinha água encanada naquela época, pegava água pros outros... . Os meus amiguinhos, era tudo criança igual eu... a gente ia no poço junto buscar água... a gente não tinha tempo pra conversa" (Vilma).

Muitas relataram diversos tipos de violência, inclusive sexual, além da questão do alcoolismo de familiares:

"Quando ela [a tia] teve o último neném, a mamãe me mandou pra casa dela pra tomar conta dos filhos... . Justamente, no dia do nascimento do filho dela, foi quando... eh...eu [risos nervosos] 
eu fui... é... estuprada... é ... no quarto dos filhos, pelo marido dela... . Quando a bomba estourou [quando souberam do fato], ... a vítima foi ele... . Eu fui a vilã, fui eu que seduziu..." (Juliana).

"Meu pai, ele estava no quarto deitado, assim, mas a correia dobrada já, correia de couro cru que ele tinha... ele me pegou pelo braço, já foi me pegando [batendo], mas foi uma coça que eu achei exagero do meu pai... eu urinei o quarto todinho, de tanto que eu apanhei... meu corpo ficou todo cheio de vergão" (Vilma, que apanhou por fazer desenhos com giz na parede externa da cozinha).

"Ele [o pai] foi me buscar na escola dizendo que quem estudava à noite era... [sussurro] 'puta'... vagabunda!! [disse ele]" (Vilma, aos 17 anos, quando trabalhava de dia e foi proibida de estudar à noite).

A capacidade de resistência frente a tantas adversidades foi por elas atribuída, especialmente, à maternidade, pelo desejo de proporcionarem aos filhos uma vida melhor.

Esses cenários explicitam como as identidades de gênero vão sendo forjadas nas experiências de classe e de raça/etnia. As situações de pobreza, que freqüentemente geram desagregação familiar e violência, marcaram profundamente essas mulheres. Ao constituírem seus núcleos familiares, buscaram superar as limitações e constrangimentos colocados pelas inúmeras adversidades. As formas como se percebem enquanto gênero irá elucidar melhor essas questões.

\section{Vale a pena ser mulher? As representações} de gênero

Sobre uma imaginária e lúdica possibilidade de poderem escolher entre a condição masculina e feminina, caso pudessem renascer, as entrevistadas expuseram as contradições de gênero como as percebem. Apesar de ter havido uma escolha eqüitativa entre o desejo de ser mulher (6) e de ser homem (6), emergiu uma representação eminentemente negativa sobre o masculino, caracterizando os homens como seres egoístas, que não compartilham as tarefas no lar e o cuidado com os filhos, como ilustrado pelos depoimentos:

"À noite, ele [marido] sempre gostou de sair com os colegas, de tomar chope, chegava em casa tarde da noite, ainda levava colega... . Às vezes, eu tava deitada, [ele] me chamava, eu levantava pra ver alguma coisa [servi-los]" (Mariana).

"Eu escolheria ser homem porque homem não tem tanto peso nas costas pra carregar igual a gente, mulher... . Porque tudo recai sobre a responsabilidade da mulher: é filho, é casa, é empregada, é obrigações... tudo" ( Letícia).

"Não havia divisão [de tarefas]... . A responsabilidade dele [marido] era com o trabalho dele.
Em casa, ele ia sair, ia jogar bola, ele ia assistir televisão, ele ia ler um livro, mas jamais fazer alguma coisa" (Claudia).

Mesmo admitindo o desemprego como uma situação que fragiliza o provedor masculino, muitas julgam que os homens não investem na própria escolarização e não se empenham para obter ou manter um emprego, mesmo quando se trata de buscar provisões para a família:

“Eu acho que se [o homem] correr atrás, se procurar, acho que encontra alguma coisa pra fazer, como a gente [mulher] encontra uma faxina... não tem que ver [escolher] o serviço, tem que encarar..." (Rafaela).

“Não, eles preferem se dedicar à bebida, ou de repente, arrumar umas 10 mulheres pra amante, pra suprir... eu não sei [o quê]...” (Juliana).

"Aí, eles [homens] vão deixando muita coisa passar.. muita coisa pra trás... aí, a gente vai tomando a frente... porque eles ainda tão naquela coisa do barzinho com os amigos... e enquanto eles tão no barzinho com os amigos, as mulheres tão indo pra escola, entendeu? Enquanto eles tão namorando 10, você tá fazendo outra coisa, tá se especializando, tá arrumando outra atividade..." (Renata).

Porém, nenhum depoimento sinalizou qualquer referência crítica a uma sociedade injusta e desigual e/ou aos processos que vêm gerando extenso desemprego, precarização do trabalho, inclusive o feminino, entre outras conseqüências que afetam, de forma dramática, as condições de subsistência de homens e mulheres da classe trabalhadora.

Por outro lado, as entrevistadas identificaram numerosos atributos femininos "positivos", geralmente relacionados à condição materna. Por serem "mães", as mulheres se tornam verdadeiras "guerreiras":

"A mulher.. ela é mais sensível, ela capta os problemas, ela vê o mundo de uma forma diferente do homem... ela não olha só a parte externa do problema, principalmente por ser mãe" (Juliana).

Porém, alguns depoimentos problematizaram a "liberdade" supostamente conquistada pelas mulheres ao custo de uma sobrecarga de atribuições:

“As [mulheres] 'um pouco menos pobres' caíram numa roubada, porque esse negócio de queimar sutiã: 'ah, vamos pra rua... temos que trabalhar, trabalhar, trabalhar', acarretou a dupla...e até a tripla jornada.... No meu caso... seriam cinco jornadas [risos]. E isso ainda é muito comum..." (Gabriela).

"A mulher continua trabalhando do mesmo jeito, a mulher trabalha [fora de casa], vai pra casa, limpa, cozinha, lava, passa, tudo do mesmo jeito" (Daniela). 
Portanto, concomitante à crítica sobre a exploração do trabalho feminino, subsiste uma representação do feminino ideologicamente "naturalizada" na maternidade, explicando e justificando a super exploração do trabalho feminino, produtivo e reprodutivo. Essa ideologia, a nosso ver, obscurece a compreensão das inter-relações entre a condição de gênero e o sistema capitalista, que explora a maioria da população trabalhadora, homens e mulheres 9,10,19,20,21.

É nesse contexto social mais amplo que iremos interpretar os significados do cigarro para essas mulheres.

\section{O "fumar" na visão das entrevistadas}

Ao explorarmos a trajetória do tabagismo em suas vidas, as entrevistadas resgataram as formas como o cigarro se introduziu em seus cotidianos, dando especial ênfase aos momentos de gestação e de criação dos filhos, indicando as questões ideológicas de gênero aí imbricadas, tal como a expectativa social da "boa mãe", entre outras.

\section{Motivos da experimentação: vivenciando} precocemente as contradiçõoes de gênero

Ao aprofundarmos a discussão sobre a idade de início da experimentação, captou-se um fato que desfaz o mito de que o início do fumar ocorre, geralmente, na juventude e com os pares. A maioria das entrevistadas que declarou, nas fichas de inscrição do programa, que havia começado a fumar com amigos, pôde perceber, nas entrevistas, que o início, propriamente dito, ocorreu em suas casas, acendendo cigarros para parentes que viviam sob o mesmo teto. Supomos que esse "esquecimento" ocorra pelo fato das entrevistadas não considerarem como iniciação ao tabagismo as experimentações com familiares que são modelos de comportamento e afeto, tais como pais, avós, irmãos ou tias.

A maioria delas (10), pela facilidade de acesso ao cigarro dentro da própria casa, começou a fumar entre 5 e 13 anos de idade, sendo este dado alarmante, já que, quanto mais precoce o início do fumar maior a probabilidade de se desenvolver determinadas doenças e transtornos psíquicos na vida adulta. Abaixo, o depoimento de Gabriela que, muito jovem, iniciou o fumo com o pai, aos 5 anos de idade: "Com 5 anos eu comecei a acender o cigarro do meu pai... . Papai não pedia a ela [mãe] pra acender porque sabia que ela não gostava... . Então, ele sentava: 'ah, pega um cigarro pra mim, acende lá no fogão' ... Quando meu pai descobriu que eu fumava... descobriu... quando ele aceitou, disse assim: 'aprendeu a fumar com seus amigos'... [e eu] 'papai, pára de ser cara de pau! Você me fazia...' [acender cigarros] [risos]”.

O depoimento de Juliana aponta o quanto o cigarro também pode estar associado a identificações afetivas positivas: "Eu amo a minha tia... . E a gente tava sempre se abraçando, né... e eu sentia [o cheiro do cigarro na boca]. Porque na minha infância eu não tive carinho... sabe que eu não tinha percebido isso? Cara, eu não tinha percebido isso! Puxa, ela me deu carinho!... [eu acendia o cigarro] e levava pra ela...".

Quando a dependência sorrateiramente se instala, surgem as estratégias para mantê-la.

"Roubava dela [da tia], do meu avô... e ... vixe! Aí, quando eu vi, eu já tava fumando toda hora, todo dia!" (Juliana).

"Agora você vê, né, se precisasse [de dinheiro] pra uma comida, não tinha... eu sempre pegava da minha tia [risos], do meu avô... e pegava um dinheirinho de mamãe... I Ia pra escola a pé [pra poder comprar cigarro]" (Juliana).

"Eu roubava cigarro deles... roubava porque não trabalhava..." (Rafaela).

Até recentemente, as mulheres eram expostas como símbolos de pureza e ingenuidade, incompatíveis com o uso de bebida alcoólica e de cigarro, sendo estes hábitos restritos aos homens. Em uma leitura crítica de gênero, pode-se supor que as entrevistadas vivenciaram alguns conflitos que perpassam a feminilidade, traduzidos por mensagens contraditórias, tais como ser feminina, dependente e frágil, e poder adotar um hábito masculino, associado à força e independência 22 .

A difícil vida de mulher: o cigarro no enfrentamento das contradições de gênero

A grande maioria das entrevistadas relatou utilizar o cigarro como forma de obter alívio quando em contato com determinados sentimentos, tais como ansiedade, raiva, impotência, solidão ou rejeição.

"Quando eu me sentia muito rejeitada... isso me dava vontade de fumar..." (Gabriela).

"Aliviar a irritação, aliviar a ansiedade, aliviar a impotência pra resolver alguma coisa... eu acho que ele [cigarro] teve presente em tudo que eu fiz... me irritava brigar, me irritava botar aquilo que eu tava sentindo pra fora... eu fumava... fechava a minha boca com o cigarro e aquilo passava" (Renata).

“...[fumava] toda vez que me aborrecia [referindo-se a apanhar do pai e irmãos]...” (Vilma).

Outras justificativas também foram apontadas, muitas associadas a situações de rotina relacionadas ao gênero, tais como a sobrecar- 
ga advinda do acúmulo de trabalho, produtivo e reprodutivo e, correlatamente, as cobranças e conflitos conjugais que geram grande estresse e desgaste, entre outras que induzem as mulheres a buscar o suporte do cigarro:

"Serviço, agitação de serviço, cobranças, trabalho... acaba ficando sobrecarregada, e é o que acontece comigo até hoje..." (Claudia).

“Aí, veio o estresse, depois de casada, filho e tudo [trabalho na rua e em casa], ai que fumava mais ainda..." (Letícia).

"Quando eu me aborrecia muito, ficava nervosa, situações, assim, de estresse, de nervosismo, ou muito trabalho... . Era cozinha, era filho, era roupa, era lavar, era passar, era casa pra limpar... então, aquilo me dava mais vontade de fumar..." (Letícia).

Alguns relatos mostraram situações de muito sofrimento, que expõem a violência social em suas várias facetas. Porém, as mulheres, em sua solidão, recorrem ao suporte proporcionado pelo ato de fumar. O caso de Rafaela, que passou por uma grande dor ao perder um filho assassinado, ilustra essa situação: "Ah, era mais solidão... quando eu pensava muito nele [no filho], quando eu pensava muito nos meus pais, quando, às vezes, precisava e não tinha ninguém pra me orientar, pra mim falar... [fumava]". Sem acesso a nenhum atendimento especializado em um momento como esse, ela lançava mão do cigarro enquanto um suporte barato, de fácil acesso e que proporcionava alívio, mesmo que momentâneo, para tantos sentimentos dolorosos.

Juliana, portadora de um câncer, também verbaliza o que significa não ter com quem dividir suas preocupações, tendo de enfrentar, solitariamente, o medo da morte: "Eu acho que essa carência, né? Essa coisa de tá carregando o mundo nas costas, tá carregando os problemas de família nas costas, eu tô muito cansada... eu creio que seja esse o meu apoio [o cigarro]... . Não tenho com quem conversar, eu não tenho onde descarregar.. eu não tenho ninguém mesmo pra falar dos problemas... eu fumo quando tô triste, eu fumo quando tô alegre... quando tô tensa, entendeu? Não tem [jeito]... é automático...".

Outros depoimentos, no mesmo sentido, relacionaram o cigarro a um suporte para os momentos de intenso e solitário sofrimento:

"Foi quando eu descobri que meu filho é soropositivo... foi muito difícil... muito difícil..." (Isabela).

“Quando eu pensava, assim, nas dificuldades [que passava na vida], nas cachaças do cara [marido], aí, eu ia fumar mesmo, não queria saber não..." (Vilma).
Representações positivas do fumar: o cigarro "companheiro" e como "fonte de prazer"

Dentre os atributos mais mencionados sobre o significado do fumar, surgiram duas categorias que, embora familiares aos que atuam neste campo, estiveram presentes de forma muito significativa nos depoimentos: o cigarro companheiro e fonte de prazer.

O cigarro "companheiro" é associado ao enfrentamento de situações relacionadas às contradições entre mundo público e familiar, aos (raros) momentos de encontro consigo própria, ao alívio dos sentimentos "negativos" e, por fim, como compensação da solidão:

"Então, eu costumava dizer que o cigarro era meu companheiro, eu já não me sentia solitária. Eu tinha um amigo, que era meu cigarro, entendeu? Então, eu ficava... passava noites acordada. E eu sempre tive esse negócio de escrever, de tudo eu escrevia. Então, eu passava a noite acordada, era eu, o lápis e um cigarro" (Mariana; grifo nosso).

"Se eu tava nervosa, se vinham lembranças que eu não queria lembrar [referindo-se ao abuso sexual que sofreu], o cigarro era meu amigo, meu companheiro, era assim que eu me sentia, né?" (Daniela; grifo nosso).

"Ah, ele [o cigarro] fazia [companhia] e muito! Quando eu me sentia triste [com a morte do filho], eu pegava o cigarro, ficava pensando e ali vai fumando, fumando, fumando... aí, passava, pronto..." (Rafaela).

"Atualmente, eu achava que [com o cigarro] tava com alguém, acompanhada com alguém, nunca tava sozinha... . Tanto é que eu sinto falta dele [do cigarro] quando eu tô sozinha. À noite, aquele silêncio [em casa], eu sinto mais falta [do cigarro]" (Luzia).

É também "companheiro" no enfrentamento de situações de estresse, no trabalho ou em casa:

"Minha primeira reunião [de trabalho], $c a$ ramba, a mão tremendo... botou o cigarro [na boca], a mão parou de tremer imediatamente [risos]... e até me acostumar com a nova situação - que sempre custa, né? - [fumou muito]" (Renata).

"Eu passei a fumar muito mais depois que eu casei... eu fumava 2 [maços], dependendo do mês do aborrecimento, sabe [risos], eu já fumei até 3 maços de cigarro por dia" (Vilma).

"E eu acho que, [como] conseqüência disso [problemas no casamento], eu me agarro ao meu amor, que é o cigarro" (Juliana).

O cigarro é, assim, evocado de forma ambígua, dicotômica, contraditória: simultaneamente, dá (prazer) e tira (a vida), é amigo (apoio) e inimigo (mata). O marketing de venda utiliza 
mensagens antagônicas, alardeando a liberdade de escolha para fumar, quando, na verdade, as pessoas se tornam prisioneiras do tabaco; associam o cigarro a esportes radicais, quando se sabe que as atividades físicas são incompatíveis com o fumo; falam de beleza e riqueza, quando a aparência envelhece e o dinheiro escoa entre remédios e cirurgias que poderiam ser evitadas; além, naturalmente, dos incalculáveis gastos com a compra do produto. Abaixo, as percepções de algumas entrevistadas sobre essas ambigüidades:

"Pois eu te digo que ele [o cigarro] é o melhor e o pior amigo que você tem. Porque ele é o melhor, porque ele tá com você quando você tá triste, quando você tá alegre, quando você tem insônia, quando você tá agitada, quando você tá calma, ele tá ali do seu lado, ao alcance da sua mão.... Ele éo pior porque ele te mata, mas ele causa um prazer muito grande... . Na verdade, eu sinto muita falta.... fiquei 5 meses sem fumar, 5 meses sentindo falta diariamente... é assim, num momento que eu não agüento mais, eu pego o cigarro, mas até aí, eu já mordi minha sombra..." (Gabriela).

"Ele [o cigarro] é meu amigo, mas eu odeio ele... eu odeio o cigarro, eu odeio a fumaça do cigarro, eu odeio tragar, mas eu não consigo me libertar... ele é meu amigo, sim, ele é meu 'amigo traíra'... é um amigo que não pode se confiar... ele é meu amigo, mas tá me matando...” (Juliana).

O cigarro significado como "fonte de prazer" emerge associado a um quase-ritual, realizado nos raros momentos em que se descansa dos incontáveis e incessantes "deveres" e solicitações das demandas da casa, do trabalho, dos filhos e de outros familiares, criando momentos íntimos de reflexão e paz, a sós consigo mesmas, em contextos de vida com poucas oportunidades de privacidade, relaxamento e intimidade:

"É que eu passei a ter muitas atribuições [após a separação] e eu pensava assim, que eu, na verdade, eu não fazia nada, assim, não ia a um cinema, não ia a um teatro... ia sim, mas pra levar o meu filho pra uma peça infantil... então, o cigarro era uma coisa que eu gostava... Era um prazer que eu tinha" (Claudia).

"Tinha os filhos, que eu acho que toda mulher normal, entre aspas, tem prazer [com os filhos]. De resto, eu acho que era trabalhar... que eu me sentia bem trabalhando. Acho que, depois da minha separação... eu acho que o prazer mesmo que eu levava, eu canalizava pro cigarro" (Renata).

"[Prazer?] o cigarro... é só o cigarro e os meus filhos...” (Letícia).

"Aquela batalha diária ... [o cigarro] era o meu companheiro, eu chegava em casa e, para dormir, para descansar, fumava antes de dormir... aquele momento meu, era sentar para ver televisão e o cinzeiro ficar aqui e o cigarrinho do lado, e fumar.. aí, ali foi aumentando o vício, né?" (Daniela).

"Às vezes, eu ficava, assim, quase subindo pelas paredes [com muitas atribuições de trabalho, casa, filhos], era eu acender o cigarro, parece que aquilo me acalmava, relaxava..." (Letícia).

Portanto, mais do que simplesmente apoio em situações difíceis, fumar também se transforma em fonte de prazer, sendo, muitas vezes, a única possível neste momento de "transição de gênero", em que as mulheres "...não somente 'ajudam' como também começam a ser responsabilizadas, e a se considerarem responsáveis, pela provisão de renda, mesmo (ou, principalmente) tendo filhos menores" 9 (p. 105).

Se entendemos, como Bordo 23, que algumas "patologias" podem expressar uma forma de protesto, expondo, por meio da doença e do corpo, o que não pode ser dito usando-se a voz coletiva, política, pergunta-se: o quanto o cigarro, usado como escape para as contradições da vida, pode contribuir para "calar" a voz das mulheres neste momento histórico 4 ?

Como visto, o tema tabagismo é uma questão complexa e perpassada pelas contradições de gênero contemporâneas. Pudemos captar, por intermédio desta pesquisa, como e o quanto o tabagismo aprofundou suas raízes na vida das mulheres e o quão complexo e pertinente às relações sociais é o ato de cessação, o que nos sinaliza para a importância de se adotar abordagens interdisciplinares, tanto na pesquisa e na assistência às mulheres tabagistas, quanto no campo das estratégias de prevenção e promoção da saúde.

\section{Considerações finais}

A pesquisa evidenciou aspectos importantes do fumar feminino e que, a nosso ver, merecem ser considerados pelos que atuam no campo da saúde, sejam formuladores, gestores e/ou os profissionais de saúde que atendem diretamente a população usuária do SUS. Entre outras questões, os dados revelaram o quanto uma compreensão mais abrangente do tabagismo feminino demanda um paradigma de conhecimento que supere a visão fragmentada do ser humano, o que abre novas perspectivas para se assistir, de forma integral, as necessidades mais amplas de vida e saúde das mulheres, tal como preconizado pelo Programa de Assistência Integral à Saúde da Mulher 3.

No campo da assistência à saúde das mulheres tabagistas, o enfoque crítico de gênero adotado pôde revelar o quanto a sobrecarga de trabalho, reprodutivo e produtivo, as incessan- 
tes demandas sócio-familiares e as contradições que as mulheres estão vivendo e enfrentando na sociedade contemporânea podem potencializar o fumar feminino. Tal como apontado pelas personagens desta pesquisa, a associação do cigarro a um "companheiro", que as ajuda a suportar o enorme peso que sobre seus ombros vem recaindo, não pode ser desconsiderada quando se deseja alcançar sucesso na abordagem para a cessação, assim como para se conquistar a adesão ao difícil percurso da superação de tão grave dependência.

Assim, como já declaramos anteriormente 4, reafirmamos aqui a necessidade de considerarmos, na pesquisa e na assistência à saúde das mulheres, particularmente no tabagismo feminino, os determinantes sociais, culturais e políticos dos processos saúde/doença, neles incluídos a dimensão de gênero. Como milhares de mulheres, em seus movimentos de luta, já alertam há quase um século, se a condição feminina não é “destino biológico", é passível, por meio da ação política coletiva, de ser transformada. Portanto, a produção de conhecimentos que assumam uma posição crítica sobre essa sociedade injusta e opressora torna-se importante ferramenta para subsidiar uma ação transformadora voltada para a construção de uma sociedade baseada na justiça social, em seu sentido amplo.

\section{Resumo}

O artigo apresenta os principais resultados de uma pesquisa que investigou, sob a ótica crítica e de gênero e da abordagem qualitativa, os significados simbólicos e concretos do fumar feminino. Foram realizadas 14 entrevistas semi-estruturadas com mulheres tabagistas em diversas etapas do processo de cessação. $O$ lócus da pesquisa foi um programa de tratamento do tabagismo em um hospital público do Rio de Janeiro, Brasil. Os resultados evidenciaram o quanto o cigarro esteve imbricado em suas trajetórias sociais e de gênero, desempenhando importante papel de apoio no enfrentamento das inúmeras dificuldades de sobrevivência. Emergiu, como categoria empírica central, o “cigarro companheiro", sempre disponível para aplacar a ansiedade e a solidão, além de também ser fonte de prazer e relaxamento. O enfoque crítico de gênero evidenciou o quanto a sobrecarga de trabalho, reprodutivo e produtivo, potencializa o fumar feminino. $\mathrm{Na}$ assistência à saúde, para se conquistar a adesão das mulheres tabagistas ao difícil percurso da cessação, deve-se levar em conta os complexos entrelaçamentos entre as dimensões sociais e de gênero no estabelecimento da associação do cigarro a um "companheiro".

Tabagismo; Abandono do Hábito de Fumar; Mulheres

\section{Colaboradores}

M. T. T. Borges participou da concepção, elaboração e revisão do artigo. R. H. Simões-Barbosa colaborou na redação, edição e revisão do artigo. 


\section{Referências}

1. Berman R. Do dualismo de Aristóteles à dialética materialista: a transformação feminista da ciência e da sociedade. In: Jaggar AM, Bordo SR, editoras. Gênero, corpo, conhecimento. Rio de Janeiro: Record/Rosa dos Tempos; 1997. p. 241-75.

2. Giffin K. Estudos de gênero e saúde coletiva: teoria e prática. Saúde Debate 1995; 46:29-33.

3. Costa AM, Aquino EL. Saúde da mulher na reforma sanitária brasileira. In: Costa AM, Merchán-Hamann E, Tajer D, organizadores. Saúde, eqüidade e gênero: um desafio para as políticas públicas. Brasília: ABRASCO/Asociación Latinoamericana de Medicina Social/Universidade de Brasília; 2000. p. 181-202.

4. Trotta-Borges MT, Simões-Barbosa RH. As marcas de gênero no fumar feminino: uma aproximação sociológica do tabagismo em mulheres. Ciênc Saúde Coletiva; no prelo.

5. Trotta-Borges MT. Tabagismo em mulheres: as marcas de gênero no fumar feminino. [Dissertação de Mestrado]. Rio de Janeiro: Instituto de Estudos em Saúde Coletiva, Universidade Federal do Rio de Janeiro; 2007.

6. Simões-Barbosa RH. Mulheres, reprodução e AIDS: as tramas da ideologia na assistência à saúde de gestantes HIV+ [Tese de Doutorado]. Rio de Janeiro: Escola Nacional de Saúde Pública, Fundação Oswaldo Cruz; 2001.

7. Kergoat D. Relações sociais de sexo e divisão sexual do trabalho. In: Lopes MJ, Meyer DE, Waldow VR, organizadores. Gênero e saúde. Porto Alegre: Artes Médicas; 1996. p. 19-27.

8. Saffiotti HIB. Violência de gênero no Brasil atual. Revista Estudos Feministas 1994; N Esp:443-61.

9. Giffin K. Pobreza, desigualdade e eqüidade em saúde: considerações a partir de uma perspectiva de gênero transversal. Cad Saúde Pública 2002; 18 Suppl:103-12.

10. Brito JC. Enfoque de gênero e relação saúde/trabalho no contexto de reestruturação produtiva e precarização do trabalho. Cad Saúde Pública 2000; 16:195-204.

11. Castro M. O conceito de gênero e as análises sobre mulher e trabalho. Notas sobre impasses teóricos. Cadernos CRH 1992; (17):80-105.

12. Deslandes SF, Gomes R. A pesquisa qualitativa nos serviços de saúde: notas teóricas. In: Bosi MLM, Mercado-Martínez FJ, organizadores. Pesquisa qualitativa de serviços de saúde. Petrópolis: Editora Vozes; 2004. p. 99-120.
13. Bosi MLM, Mercado-Martínez FJ. Introdução: notas para um debate. In: Bosi MLM, Mercado-Martínez FJ, organizadores. Pesquisa qualitativa de serviços de saúde. Petrópolis: Editora Vozes; 2004. p. 23-71.

14. Thompson JB. Ideologia e cultura moderna: teoria social crítica na era dos meios de comunicação de massa. Petrópolis: Editora Vozes; 1995.

15. Minayo MCS. O desafio do conhecimento: pesquisa qualitativa em saúde. 8a Ed. São Paulo: Editora Hucitec; 2004.

16. Parker R, Herdt G, Carballo M. Cultura sexual, transmissão do HIV e pesquisas sobre AIDS. In: Czeresnia DM, Simões-Barbosa RH, Santos EM, organizadores. AIDS: pesquisa social e educação. São Paulo: Editora Hucitec/ABRASCO; 1995. p. 17-45.

17. Jelín E. Las familias en América Latina. Santiago de Chile: ISIS Internacional; 1994. (Ediciones de las Mujeres, 20).

18. Bruschini C. Women and labor in Brazil. Revista Estudos Feministas 1994; 3:201-11.

19. Laurell AC. Globalización y reforma del Estado. In: Costa AM, Aquino EL. Saúde da mulher na reforma sanitária brasileira. In: Costa AM, Merchán-Hamann E, Tajer D, organizadores. Saúde, eqüidade e gênero: um desafio para as políticas públicas. Brasília: ABRASCO/Asociación Latinoamericana de Medicina Social/Universidade de Brasília; 2000. p. 35-60.

20. Silveira ML. Políticas públicas de gênero: impasses e desafios para fortalecer a agenda política na perspectiva da igualdade. In: Godinho T, Silveira ML, organizadores. Políticas públicas e igualdade de gênero. São Paulo: Coordenadoria Especial da Mulher; 2004. p. 65-75. (Cadernos da Coordenadoria Especial da Mulher, 8).

21. Giffin K. Esfera da reprodução em uma visão masculina: considerações sobre a articulação da produção e da reprodução, de classe e de gênero. Physis (Rio J) 1994; 4:23-40.

22. Anyon J. Intersecções de gênero e classe: acomodação e resistência de mulheres e meninas às ideologias de papéis sexuais. Cad Pesqui 1990; (73):13-25.

23. Bordo S. O corpo e a reprodução da feminilidade: uma apropriação feminista de Foucault. In: Jaggar AM, Bordo SR, editoras. Gênero, corpo, conhecimento. Rio de Janeiro: Record/Rosa dos Tempos; 1997. p. 19-41.

Recebido em 09/Nov/2007

Versão final reapresentada em 05/Mar/2008

Aprovado em 24/Abr/2008 